\title{
PERENCANAAN EXTERNAL FIRE FIGHTING UNTUK KAPAL PEMADAM KEBAKARAN
}

\author{
H A R I N I \\ Fakultas Teknik, Program Studi Teknik Mesin \\ Universitas 17 Agustus 1945 Jakarta \\ harini_rahardjo@yahoo.com
}

\begin{abstract}
ABSTRAK
Dasar dari penulisan tugas akhir ini adalah merancang sistem pemadam kebakaran (External Fire Fighting) untuk kapal pemadam kebakaran. Perlunya kapal pemadam kebakaran, karena meskipun kapal sudah dilengkapi dengan sistem pemadam kebakaran, akan tetapi kalau api sudah terlanjur membesar, maka sistem pemadam kebakaran internal tidak mampu lagi untuk memadamkan. Kondisi penyemprotan yang direncanakan adalah Kapasitas air yang disemprotkan sebesar $1200 \mathrm{~m}^{3} / \mathrm{h}$ dengan jarak jangkauan semprot mendatar (throw range) $150 \mathrm{~m}$.

Pelaksanaan perencanaan dilakukan dengan perhitungan-perhitungan analitis disertai dengan pengalaman bekerja diperusahaan pembuat kapal pemadam serta data-data yang ada di pasaran.

Dari hasil perencanaan diperoleh bahwa untuk mendapatkan jangkauan penyemprotan sejauh $150 \mathrm{~m}$ dengan kapasitas semburan sebesar $120 \mathrm{~m}^{3} / \mathrm{h}$, pompa harus memiliki minimal head $101.05 \mathrm{~m}$. Daya yang dibutuhkan untuk penggerak pompa sebesar $474.5 \mathrm{~kW}$
\end{abstract}

Kata kunci : Pemadam kebakaran, sistem pemipaan, pompa

\begin{abstract}
The basis of this thesis is to design a fire extinguishing system (External Fire Fighting) for the fireboat. Importance fireboat, because although the ship is equipped with a fire extinguishing system, but if the fire had already enlarged, the internal fire extinguishing systems are no longer able to extinguish. The planned spraying conditions is sprayed water capacity of $1200 \mathrm{m3} / \mathrm{h}$ with a horizontal spray reach distance (throw range) $150 \mathrm{~m}$.

Implementation planning is done with analytical calculations along with experience of working in the
\end{abstract} company shipbuilders fire and the data that exist on the market.

The results obtained that the plan to get coverage spraying distance of $150 \mathrm{~m}$ with bursts capacity of 120 $\mathrm{m} 3 / \mathrm{h}$, the pump must have a minimum of $101.05 \mathrm{~m}$ head. The power needed to drive the pump at $474.5 \mathrm{~kW}$

Keywords : External fire fighting, piping systems, pumps 


\section{LATAR BELAKANG}

Alat pemadamkebakaran di kapal sangat terbatas kemampuannya. Akan tetapi pemadam kebakaran internal hanya mampu mengatasi kebakaran yang kecil saja. Jadi ketika api sudah terlampau besar, alat pemadam yang ada di internal kapal tidak mampu lagi dipergunakan memadamkan api yang sudah berkobar. Untuk itu diperlukan alat pemadam dari luar kapal. Untuk itu sangat penting keberadaan kapal pemadam kebakaran

\section{TUJUAN PERANCANGAN}

Untuk menentukan sistem pemipaan dan pompa yang sesuai yang dipergunakan untuk External Fire Fighting pada kapal Penyelamat

\section{METODE PERENCANAAN}

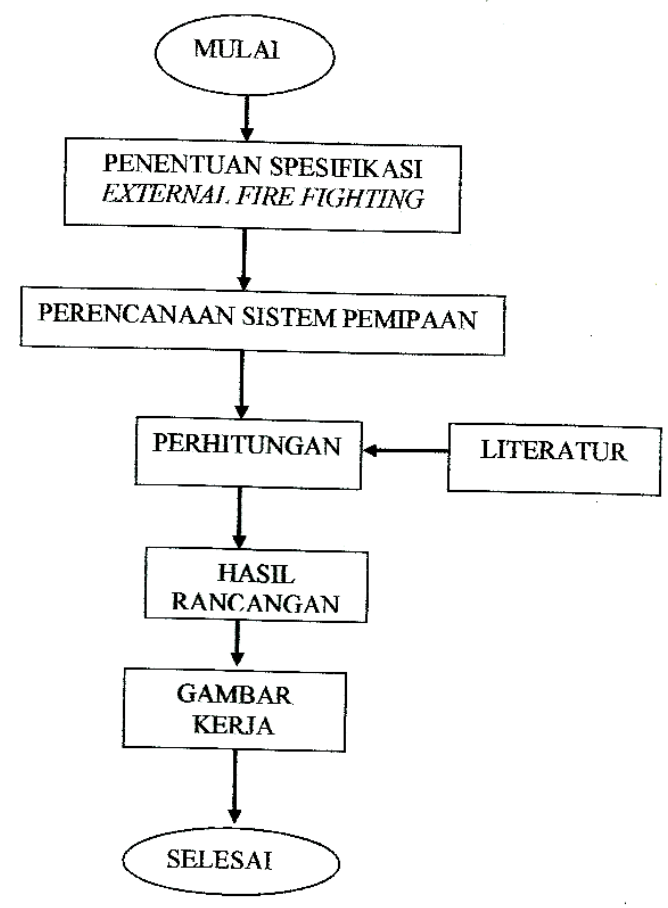

Gambar 1. Alur proses perencanaan 
Sketsa external figthing system

Spesifikasi External Fire
External fire dirancang untuk kapasitas semburan air dari monitor adalah sebesar $1200 \mathrm{~m}^{3} / \mathrm{h}$, dengan jarak semprot horizontal (trow range) sejauh $150 \mathrm{~m}$, dan putaran poros pompa $1800 \mathrm{rpm}$.

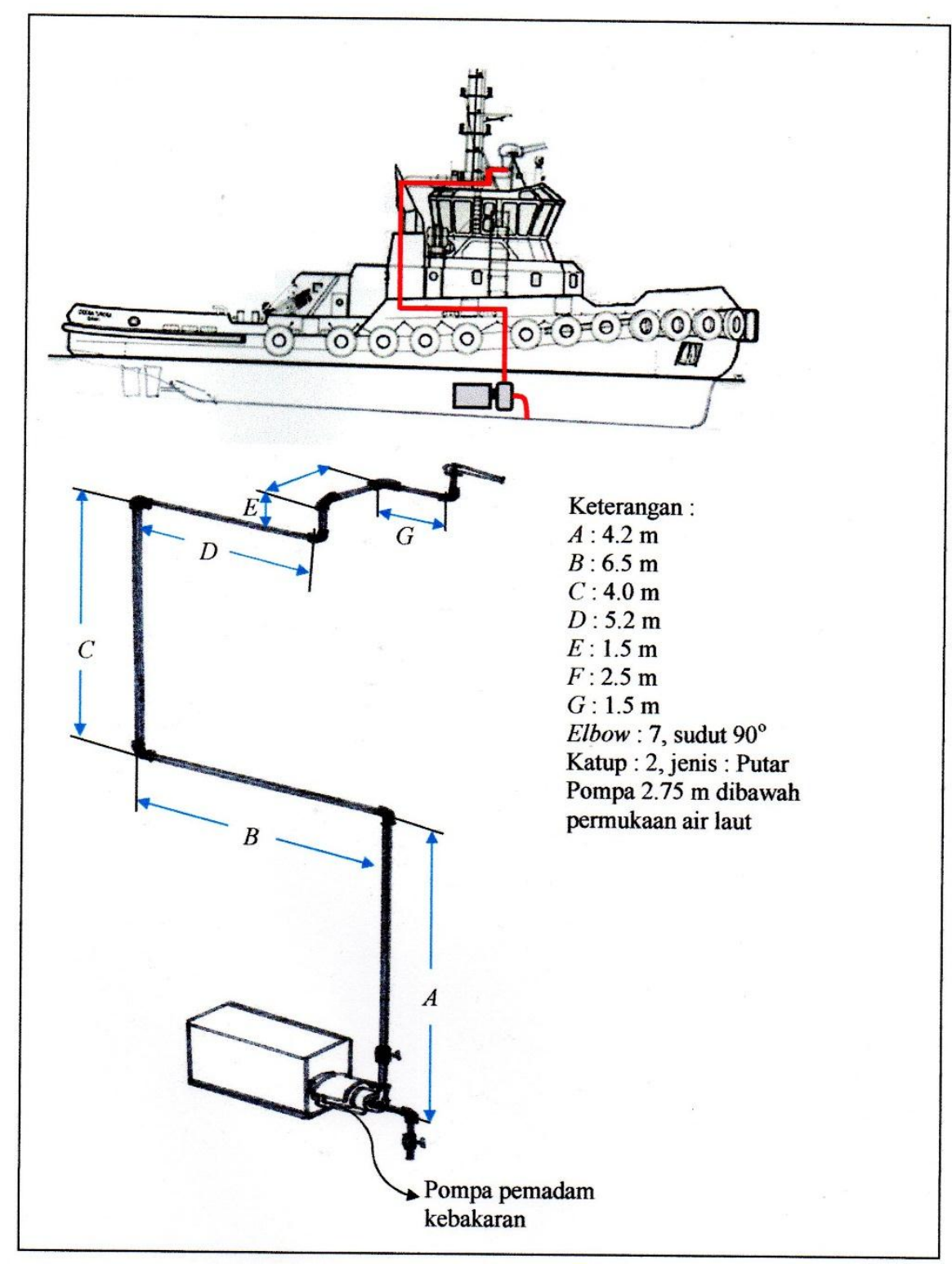

Gambar 2. Sketsa external fire fighting system

\section{DATA}

\section{Sistem Pemipaan :}

Dasi sketsa sistem pemipaan untuk external fire adalah :

Tinggi isap $\left(h_{s}\right):-2.75 \mathrm{~m}$

Tinggi Tekan $\left(h_{d}\right): 4.2+4.0+1.5=9.7 \mathrm{~m}$

\section{Panjang Pipa :}

$L=4.2+6.5+4.0+5.2+1.5+2.5+1.5=25.4$

$\mathrm{m}$

\section{a. Elbow}

Jumlah : 7 , sudut elbow : $90^{\circ}, R / D=1.5$

b. Katup

Jumlah katup : 3, jenis : Katup putar 


\section{PERHITUNGAN}

Kapasitas aliran rancangan $(Q): 1200 \mathrm{~m}^{3} / \mathrm{h}$ atau senilai $5.284 \mathrm{gal} / \mathrm{min}$. Menurut Tyler G Hicks, TW Edward (1996 : 57), diameter pipa yang disarankan untuk kapasitas aliran antara 4.000 sampai $8.000 \mathrm{gpm}$ adalah 8 inch. Dimana pipa ukuran 8 inch, memiliki dimensi sebagai berikut :

Diameter luar $\quad(D o) \quad: 219.8 \mathrm{~mm}$

Schedule: $2.77 \mathrm{~mm}$ Extra Strong (XS)

Diameter dalam $(D i) \quad: 214.26 \mathrm{~mm}$

Kecepatan aliran :

$$
V=\frac{Q}{A}
$$

Dimana :

$$
A=\frac{\Pi D i^{2}}{4}
$$

Maka :

$$
A=\frac{\Pi 0.21426^{2}}{4}=0.036 \mathrm{~m}^{2}
$$

Kapasitas aliran $(Q) \quad: 1200 \mathrm{~m}^{3} / \mathrm{h}$ atau 20 $\mathrm{m}^{3} / \mathrm{min}$

Sehingga kecepatan aliran $(V)$ :

$$
V=\frac{Q}{A}=\frac{20}{0.036}=556(\mathrm{~m} / \mathrm{min})
$$

Untuk mengetahui besarnya head total yang harus dapat diatasi oleh pompa dapat dihitung dengan menggunakan persamaan berikut :

$$
H=h_{a}+\Delta h_{p}+h_{l}+\frac{V_{d}^{2}}{2 g}
$$

\section{Head Statis pompa $\left(h_{a}\right)$}

Besarnya head statis atau tinggi isap statis adalah :

Tinggi isap $\left(h_{s}\right):-2.75 \mathrm{~m}$

Tinggi Tekan $\left(h_{d}\right): A+C+E=4.2+4.0+1.5=9.7$

$\mathrm{m}$

Sehingga head statis pompa $\left(h_{a}\right)$

$$
h_{a}=\left(h_{s}+h_{d t}\right)=(-2.75)+9.7=6.95 m
$$

Head Tekanan $\left(\Delta h_{p}\right)$

Tekanan udara dari suatu ketinggian (yang diukur dari ketinggian permukaan air laut):

$$
P a=10,33\left[1-\frac{0,0065 \cdot h}{288}\right]^{5,256}
$$

Dimana :

$\mathrm{Pa}$ : Tekanan Atmosfir standar $\left(\mathrm{m} \mathrm{H}_{2} \mathrm{O}\right)$

$\mathrm{h}:$ Ketinggian posisi yang diukur terhadap muka air laut : $6.95(\mathrm{~m})$

Maka tekanan pada ketinggian sisi ujung keluar (fire monitor)

$P a=10,33\left[1-\frac{0,0065 \cdot(6 \cdot 95)}{288}\right]^{5,256}=10.33 m \mathrm{H}_{2} \mathrm{O}$

Besarnya head tekanan adalah :

$\Delta h p=\frac{\Delta p}{\gamma}$

Dimana :

$\Delta p:$ Selisih tekanan : $10.33-10.33\left(\mathrm{mH}_{2} \mathrm{O}\right)=0$ $\left(\mathrm{mH}_{2} \mathrm{O}\right)=0.0\left(\mathrm{kgf} / \mathrm{m}^{2}\right)$

$\gamma:$ massa jenis udara $\left(\mathrm{kgf} / \mathrm{m}^{3}\right)=1,225\left(\mathrm{kgf} / \mathrm{m}^{3}\right)$

Maka head tekanan :

$$
\Delta h_{p}=\frac{0.0\left(\mathrm{kgf} / \mathrm{m}^{2}\right)}{1,225\left(\mathrm{kgf} / \mathrm{m}^{3}\right)} \approx 0(\mathrm{~m})
$$

\section{Head Kerugian (head losses)}

\section{Kerugian Head Akibat Gesekan}

Besarnya kerugian head akibat gesekan adalah :

$$
h f=\lambda\left(\frac{L}{d}\right)\left(\frac{V^{2}}{2 g}\right)
$$

Dimana :

$\lambda$ : koefisien gesekan 
$L \quad$ : panjang pipa : $15.1(\mathrm{~m})$

$d \quad$ : diameter dalam pipa : $0.214(\mathrm{~m})$

$g \quad$ : percepatan gravitasi : $9.81\left(\mathrm{~m} / \mathrm{s}^{2}\right)$

$V \quad:$ Kecepatan Aliran (m/det)

$V=\frac{Q}{A}=\frac{20}{0.036}=556(\mathrm{~m} / \mathrm{min})=9.3(\mathrm{~m} / \mathrm{s})$

Bilangan Reynold :

$R_{e}=\frac{V . D}{v}$

Dimana :

$V: 9.3(\mathrm{~m} / \mathrm{s})$

$D: 0.214(\mathrm{~m})$

$v: 1,004 \times 10^{-6}\left(\mathrm{~m}^{2} / \mathrm{s}\right)$

Maka nilai Bilangan Reynold :

$R_{e}=\frac{9.3 \times 0.214}{1,004 \times 10^{-6}}=199020.00$

$R_{e}>4000$, maka aliran bersifat turbulen

Nilai koefisien gesekan untuk aliran turbulen adalah :

$\lambda=0,020+0,0005 / \mathrm{d}$

Dimana :

$d=0.214 \mathrm{~m}$

Maka $\lambda=0.02+0.0005 / 0.214=0.0223$

Sehingga besar kerugian head akibat gesekan adalah

$h_{f}=0.0223\left(\frac{15.1}{0.214}\right)\left(\frac{9.3^{2}}{2 \times 9.81}\right)=6.9(\mathrm{~m})$

\section{Kerugian Head Akibat Adanya Fitting}

Kerugian head yang terjadi akibat adanya:

\section{A. Kerugian Diakibatkan Katup \\ Jenis Katup : Katup putar}

Jumlah : 3

Kerugian akibat adanya katup

$h_{f_{1}}=f \frac{V^{2}}{2 g}$

Dimana :

$f$ : koefisien kerugian : 0.09

$V \quad:$ Kecepatan Aliran : $9.3(\mathrm{~m} / \mathrm{s})$

$g \quad:$ percepatan gravitasi $=9.81\left(\mathrm{~m} / \mathrm{s}^{2}\right)$

Maka $h_{f_{1}}=3\left(0.09 \frac{9.3^{2}}{2 \times 9.81}\right)=1.2(\mathrm{~m})$

B. Kerugian Diakibatkan Belokan

Jenis Belokan : Belokan lengkung, $90^{\circ} \quad$ R/D $: 1.5$

Jumlah : 8

Kerugian akibat adanya belokan :

$h_{f_{2}}=f \frac{V^{2}}{2 g}$

Dimana :

$f \quad$ : koefisien kerugian untuk sudut $90^{\circ}$ untuk $\frac{R}{D}: 1.5=0.18$

Maka :

$$
h_{f_{2}}=8\left(0.18 \frac{9.3^{2}}{2 \times 9.81}\right)=6.3(\mathrm{~m})
$$

C. Kerugian Pada Ujung Pipa Masuk

Bentuk mulut pipa : lonceng dengan radius

Koefisien kerugian $f: 0,2$ untuk mulut lonceng dengan radius

$h_{f_{3}}=f \frac{V^{2}}{2 g}$

Dimana :

$f$ : koefisien kerugian $: 0.2$ 
Maka : $h_{f_{3}}=\left(0.2 \frac{9.3^{2}}{2 \times 9.81}\right)=0.9(\mathrm{~m})$

Total kerugian $\left(h_{l}\right)=$ Kerugian gesekan + Kerugian adanya Fitting

$$
\begin{aligned}
& h_{l}=h_{f}+\left(h_{f 1}+h_{f 2}+h_{f 3}\right) \\
& h_{l}=6.9+(1.2+6.3+0.9)=14.7(\mathrm{~m})
\end{aligned}
$$

\section{Head Kecepatan Keluar Ujung Pipa Tekan}

Head kecepatan pipa keluar:

$$
=\frac{V_{d}^{2}}{2 g}
$$

Dimana

$$
V_{d}=\text { Kecepatan pada ujung pipa keluar : }
$$

$9.3(\mathrm{~m} / \mathrm{s})$ dan $g: 9.81\left(\mathrm{~m} / \mathrm{s}^{2}\right)$

Maka head kecepatan pipa keluar :

$$
=\frac{9.3^{2}}{2 \times 9.81}=4.4(\mathrm{~m})
$$

\section{Head Total Instalasi Pompa}

Dengan menggunakan persamaan :

$$
H=h_{a}+\Delta h_{p}+h_{l}+\frac{V_{d}^{2}}{2 g}
$$

Dimana :

Head statis $(h a) \quad: 6.95 m$

Head tekanan $(\Delta h p): 0 \quad m$

Head kerugian $\left(h_{l}\right) \quad: 14.7 \mathrm{~m}$

Head kecepatan keluar $\left(v d^{2} / 2 g\right): 4.4 m$

Maka Head instalasi pompa :

$H=6.95+0+14.7+4.4=26.05 m$

Sebagai pompa pemadam kebakaran pada kapal penolong/pemadam, head pompa bukan hanya dari posisi saluran isap sampai pada posisi saluran buang, akan tetapi harus mampu untuk menyemprotkan air sampai pada posisi kapal yang terbakar. Untuk itu Head Total pompa pemadam kebakaran adalah Head Instalasi ditambah dengan jarak antara Fire Monitor (alat penyemprot air) sampai pada titik api. Jarak tersebut sekitar $150 \mathrm{~m}$

Jarak jatuh terjauh penyemprotan adalah pada sudut penyemprotan $45^{\circ}$. Pada segitiga $\mathrm{ABC}$, dengan sudut siku-siku di BCA, jika salah satu sudutnya $45^{\circ}$, maka sudut yang lainnya juga $45^{\circ}$ (jumlah sudut dalam segitiga adalah $180^{\circ}$ ), atau bentuk segitiganya adalah segitiga samakaki.

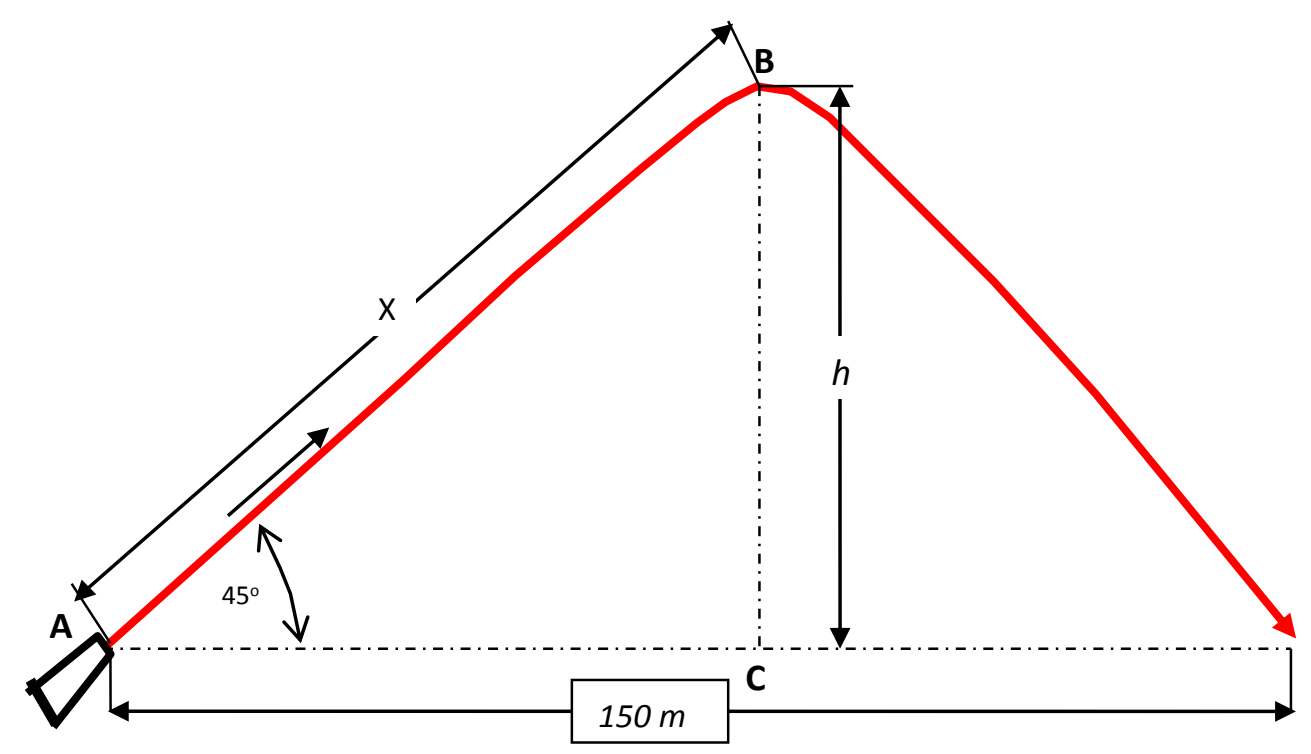

Gambar 3. Jarak jangkauan penyemprotan horizontal (throw range) 
Maka :

$$
h=B C=A C=\frac{150(m)}{2}=75(m)
$$

Sehingga Head Total Pompa :

$$
H_{T o t}=H+h=26.05+75=101.05(\mathrm{~m})
$$

\section{Kecepatan Spesifik}

Nilai kecepatan spesifik dapat diperoleh dari persamaan :

$$
n_{s}=n \frac{Q^{\frac{1}{2}}}{H^{\frac{3}{4}}}
$$

Dimana :

$n_{s}:$ Kecepatan spesifik, rpm

$Q:$ Kapasitas : $20 \mathrm{~m}^{3} / \mathrm{min}$

$H$ : Head Total pompa : $101.05 \mathrm{~m}$

$n$ : putaran poros : $1800 \mathrm{rpm}$

Maka kecepatan spesifik :

$$
n_{s}=1800\left(\frac{20^{1 / 2}}{101.05^{3 / 4}}\right) \approx 253(\mathrm{rpm})
$$

Pompa untuk pemadam, dengan $n_{s} 253 \mathrm{rpm}$, adalah pompa jenis Sentrifugal.

\section{Daya Air $\left(\mathbf{P}_{\mathrm{w}}\right)$}

Daya air dapat diperoleh dari persamaan :

$$
P w=0.163 \cdot \rho \cdot Q \cdot H(k W)
$$

Dimana :

$$
\begin{array}{ll}
Q & : 20 \mathrm{~m}^{3} / \mathrm{min} \\
H & : 101.05 \mathrm{~m} \\
\rho & : \text { Massa jenis fluida }=0.9983 \mathrm{~kg} / \mathrm{l}
\end{array}
$$

Maka

Daya Air :

$P w=0.163 x 0.9983 x 20 x 101.05 \approx 329(k W)$

\section{Daya Poros (P)}

$$
P=\frac{P_{W}}{\eta_{P}}
$$

Dimana :

$$
\begin{array}{ll}
P_{w} & : \text { Daya Air }=329 \mathrm{~kW} \\
\eta_{P} & : \text { Efisiensi pompa }
\end{array}
$$

\section{Efisiensi pompa}

Dengan $Q: 20 \mathrm{~m}^{3} / \mathrm{min}$ dan $n_{s}: 253$, maka efisiensi pompa : $\eta_{s}=84 \%$

Maka Daya Poros :

$$
P=\frac{329(k W)}{84 \%}=392(k W)
$$

\section{Daya Nominal Penggerak Mula $\left(\boldsymbol{P}_{m}\right)$}

$$
P_{m}=\frac{P(1+\alpha)}{\eta_{t}}
$$

\section{Dimana :}

$\alpha=0.15$, untuk motor bakar besar $\eta_{\mathrm{t}}=$ Efisiensi Transmisi 0.95 untuk roda gigi miring 1 tingkat

Maka :

$$
P m=\frac{392(1+0.15)}{0.95} \approx 474.5(k W) \text { atau }
$$

dibulatkan $500 \mathrm{~kW}$.

\section{Pembahasan}

Jangkauan penyemprotan horizontal dipengaruhi oleh sudut tembak dari nozel. Seperti pada gaya 
peluru, jangkauan jarak horizontal dipengaruhi oleh sudut kemiringan dari nozel. Jangkauan terjauhnya adalah pada sudut $45^{\circ}$. Sehingga yang dipergunakan sebagai dasar perhitungan adalah titik tertinggi dari penyemprotan untuk menjangkau jarak horizontal $150 \mathrm{~m}$, adalah $75 \mathrm{~m}$.

Dengan tambahan head sebesar $75 \mathrm{~m}$ selepas air dari nozel dan $26.05 \mathrm{~m}$ head dari sistem pemipaan, maka untuk menjangkau jarak semprot horizontal $150 \mathrm{~m}$, diperlukan pompa memiliki head minimal $101.05 \mathrm{~m}$.

Dengan kapasitas aliran $20 \mathrm{~m}^{3} / \mathrm{min}$, head total $101.05 \mathrm{~m}$ dan putaran poros pompa $1800 \mathrm{rpm}$, diperoleh kecepatan spesifik sebesar $253 \mathrm{rpm}$. Sehingga jenis pompa yang sesuai adalah Pompa Sentrifugal, dengan Daya Air : 392 kW. Penggerak yang dipergunakan adalah motor bakar besar, yang putarannya direduksi dengan menggunakan roda gigi miring 1 tingkat, maka diperlukan mesin dengan Daya Keluaran sebesar $474.5 \mathrm{~kW}$ atau 500 $\mathrm{kW}$.

\section{KESIMPULAN}

Dari hasil pembahasan pada bab sebelumnya, maka untuk mendapatkan hasil sesuai dengan perencanaan, maka pompa pemadam yang akan dipasang pada kapal pemadam kebakaran sebagai External Fire Fighting dengan kapasitas $1200 \mathrm{~m}^{3} / \mathrm{h}$ dan jarak jangkauan penyemprotan horizontal $150 \mathrm{~m}$, adalah sebagai berikut :

1. Pompa memiliki kapasitas aliran $1200 \mathrm{~m}^{3} / \mathrm{h}$ dengan head total minimal $101.05 \mathrm{~m}$.

2. Pompa memiliki kecepatan spesifik 253 rpm, sehingga pompa yang sesuai adalah jenis Pompa Sentrifugal.

3. Mesin penggerak menggunakan Mesin Diesel dengan daya keluaran sebesar 474.5 $\mathrm{kW}$ atau $500 \mathrm{~kW}$.

\section{SARAN}

Untuk mendapatkan sistem pemadaman kebakaran yang memiliki kemampuan/unjuk kerja yang maksimal dan usia pakai/life time yang panjang, penulis menyarankan beberapa hal sebagai berikut :

1. Spesifikasi peralatan setidaknya $15 \%$ lebih tinggi dari hasil perencanaan. Hal tersebut bertujuan agar kapasitas dan jangkauan penyemprotan lebih terjamin.

2. Karena fluida yang dipergunakan adalah air laut, maka dipergunakan material yang tahan korosi.

3. Pada pengembangan selanjunya pada pipa sisi tekan dilengkapi dengan pressure gauge, hal tersebut untuk mengetahui dengan pasti head tekan pada pompa pemadam.

\section{DAFTAR PUSTAKA}

[1] David W Smith, C.Eng., M.I.Mar. E, 1987. "Marine Auxiliary Machinery" Sixth Edition, Butterworth U.K

[2] Fritz Dietsel, Alih bahasa Dakso Sriyono, 1996. "Turbin Pompa \& Kompresor", Erlangga, Jakarta

[3] Sularso, Haruo Tahara, 2006,"Pompa dan Kompresor", Pradnya Paramitra, Jakarta

[4] Tyler G Hicks, TW Edward, Alih bahasa Zulk ifli Harahap,1996. "Teknologi Pemakaian Pompa", Erlangga, Jakarta

[5] Victor L Streeter, Benjamin Wylie, Alih bahasa Arko Prijono,1995. "Mekanika Fluida", Erlangga, Jakarta 